Research Paper:

\title{
The Effect of Self-Care Education Program on Anthro- pometric Indicators in Postmenopausal Women With Metabolic Syndrome
}

Daryadokht Masror Roudsari ${ }^{1}$, Sahab Badizadeh ${ }^{2 *}$, Leila Janani ${ }^{3}$

1. Department of Medical-Surgical, School of Nursing and Midwifery, Iran University of Medical Sciences, Tehran, Iran.

2. Department of Medical-Surgical, School of Nursing and Midwifery, International Campus, Iran University of Medical Sciences, Tehran, Iran

3. Department of Biostatistics, School of Public Health, Iran University of Medical Sciences, Tehran, Iran

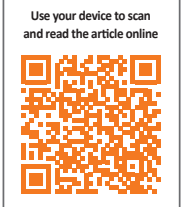

ditation: Masror Roudsari, D., Badizadeh, S. \& Janani, L., 2017. The Effect of Self-Care Education Program on Anthropometric Indicators in Postmenopausal Women With Metabolic Syndrome. Journal of Client-Centered Nursing Care, 3(3), pp. 179-188. https://doi.org/10.32598/jecnc.3.3.179

https://doi.org/10.32598/jccnc.3.3.179

Article info:

Received: 07 Feb. 2017

Accepted: 21 Jun. 2017
Keywords:

Self-care, Metabolic Syndrome, Menopause

\section{ABSTRACT}

Background: Metabolic syndrome is a disorder associated with obesity. Compared with men, postmenopausal women are at higher risk of being affected by this chronic disease. This study aimed to determine the effect of self-care education program on anthropometric indicators in postmenopausal women with metabolic syndrome.

Methods: A cluster randomized controlled trial was performed on 120 postmenopausal women aged 45-60 years with metabolic syndrome at the 8 healthcare centers of Tehran municipality. The study was carried out in the second half of 1395. In this study, healthcare centers were randomly allocated to experimental and control groups. Then, sampling was performed as targeted and accessible from each center. The intervention was done based on the educational needs of patients and according to the Orem framework. This intervention was presented as a 5 -session self-care education program. The training program was implemented within 5 weeks during. Training groups consisted of 5-7 people. Anthropometric information was investigated before and after the end ( 8 weeks) of the training program in both groups. Data were analyzed using SPSS (version 22) and STATA (version 13) software, and Chi-Square test, T-Independent test, T-Paired test and SVY environment.

Results: Our findings demonstrated that self-care training program decreased indicators (weight, body mass index, waist and hip circumference, middle arm circumference, and waist to height ratio), while no significant reduction was observed in the waist to hip ratio.

Conclusion: Present study established that self-care program based on the Orem framework has positive effects on anthropometric indicators in postmenopausal women with metabolic syndrome. Therefore, this program is recommended as a nursing intervention in patients with metabolic syndrome.

\section{* Corresponding Author:}

Sahab Badizadeh, MSc.

Address: Department of Medical-Surgical, School of Nursing and Midwifery, International Campus, Iran University of Medical Sciences, Tehran, Iran Tel: +98 (912) 7011765

E-mail:pbadizadeh@yahoo.com 


\section{Background}

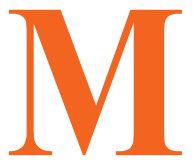

enopause in women is a potential evolutionary crisis. They spend about one-third of their lives in menopause (Kang et al. 2014). According to the World Health Organization (WHO), the definition of menopause is clinically relevant, discontinuation of menstrual bleeding without a specific cause such as pregnancy or lactation for at least 12 continuous courses. In fact, menopause is a process that stops producing hormones by the ovaries (Speroff \& Fritez 2011).

This physiological change after menopause causes the end of fertility in women. Additionally, for catching of chronic diseases caused by weighted positions such as metabolic syndrome make women more vulnerable than men (Kong et al. 2012; Speroff \& Fritez 2011). Therefore, menopause is a factor in women's vulnerability to metabolic syndrome (Kang et al. 2014).

Metabolic syndrome is a disorder associated with obesity. This syndrome is known by the components of abdominal obesity, high blood pressure, high blood lipids, and insulin resistance. The characteristic features of metabolic syndrome are its slow, chronic, and progressive nature. This syndrome causes irreversible changes in vital systems and organs such as liver, kidneys, large vessels, heart, and lungs and may be a threat to one's life.

Metabolic syndrome is diagnosed in a person when there are 3 or more of the following components: abdominal obesity and waist circumference of $88 \mathrm{~cm}$ or more; elevated blood pressure, systolic blood pressure of $130 \mathrm{~mm} \mathrm{Hg}$ or higher and/or diastolic blood pressure of $85 \mathrm{~mm} \mathrm{Hg}$ or higher; impaired glucose tolerance, fasting blood glucose level of $100 \mathrm{mg} / \mathrm{dL}$ or higher; hypertriglyceridemia, triglyceride level of $150 \mathrm{mg} / \mathrm{dL}$ or higher; and high-density lipoprotein cholesterol level lower than 50 mg/dL (Hinckle 2014; Speroff \& Fritez 2011).

It is worth noting that metabolic syndrome is the boundary between health and disease. People having 3 of the above symptoms at the same time should try to correct these abnormal cases even if they feel well. The prevalence of this disorder in adults varies between 20 $\%$ and $30 \%$ and depends on the age, race, and diagnostic definition (Ref). Moreover, the prevalence has increased significantly in recent times (Kang et al. 2014).

This increase in the prevalence of metabolic syndrome, pertaining to public health issues, needs a special atten- tion (Kang et al. 2014). Although not clearly understood, the pathogenesis and progression of metabolic syndrome could be due to several factors such as low economic and social status, low physical activity, lack of awareness, lifestyle, and absence of proper management of menopause (Speroff \& Fritez 2011; Williams et al. 2013).

Obesity is caused by the accumulation of excess triglycerides in fat cells (Speroff \& Fritez 2011). One of the major concerns in public health issues is the prevention of obesity. However, despite the health risks associated with obesity, little studies have been done on its effective prevention strategies. Obesity is important in terms of risk at different stages of life, especially after menopause; on the other hand, studies have shown that midwifery is a highrisk step for weight gain in women that at first, abdominal obesity feels like a risk (Williams et al. 2013).

The highest decreases in women's health occur with age increasing. This is the state of health of people in adulthood and afterwards is associated with their lifestyle (Kang et al. 2014). Because of increasing incidence of metabolic syndrome, prevention is the best solution (Speroff \& Fritez 2011).

Making a change in lifestyle reduces the average number of years person's disability. So, self-care is raised in the meantime. According to Orem, the ability to carry out self-care activities is called self-care power. In the continuum of health-disease, she defines a defect in selfcare as an imbalance between the ability to do self-care and the amount needed for this type of care (Aggleton \& Chalmez 2014). In fact, self-care is practicable when a person uses his knowledge, skill, and power as a source. Therefore, the person can take care of self-health independently (Alligood 2011).

The key to achieve self-care is education. Training is a purposeful, systematic, regular and designed process. Training makes learning and behavioral changes. Patient's knowledge, attitude and skill improve and the competence and ability of the patient increases in selfcare. As a result, a person performs activities that improve their health and well-being and prevent potential complications (Asadi Noogaee, Zandi, \& Nazari 2010).

Therefore, the training program is an effective policy for raising awareness and knowledge in postmenopausal women (Kwak, Park \& Kang 2014). Further, women can manage postmenopausal period with a positive attitude (Kang et al. 2014). Therefore, women in postmenopausal period need proper education due to their low self-management ability, which necessitates formulation 
of a nursing program for the health of postmenopausal women (Kwak, Park \& Kang 2014).

Considering that self-care program is effective in controlling metabolic syndrome (Ruggirero et al. 2014). As a result, behavioral change is effective through education intervention and by health professionals. Furthermore, there is a need for interventions with less tension and the possibility of further implementation in the postmenopausal women population (Williams et al. 2013). In essence, change in health behaviors to prevent, promote, and maintain health is one of the goals of patient education. This policy decreases the family's cost of treatment and the number of visits to health centers. Independence and individual ability increases in everyday life and ultimately a better age-old expectancy (Williams et al. 2013). Thus, the present study was designed to determine the effect of self-care training program on anthropometric indicators in postmenopausal women with metabolic syndrome.

\section{Materials and Methods}

\section{Study design and participants}

We performed a cluster randomized controlled trial in both groups. The study population includes a total of 120 postmenopausal women aged $45-60$ years. The women were presented with metabolic syndrome to the 8 of the 15 healthcare centers in 22 districts of Tehran municipality. The study was carried out in the second half of 1395 hijri. This research was conducted with the approval of the University Research Ethics Committee with code No. IR.IUMS.REC.1395.93136006 and registration at the Iranian Research of Clinical Trial site with code No. IRCT2017050333803N1. According to the cluster type of the study, the centers were randomly assigned in experimental and control groups using colored bullets and allocated 4 centers for each group.

The sample size was calculated for 120 people, considering to $95 \%$ confidence index and $5 \%$ probability of first type error, $20 \%$ probability of second type error and according to this study of the cluster type, therefore, by taking the cluster effect is equivalent to $1 / 5$ unit. Thus, the number of samples needed for each group was 60 ( 4 centers and 15 people from each center). Then, sampling in centers performed as targeted and accessible. To achieve this goal, first, for the diagnosis of metabolic syndrome, they were approved by the physician and presented to the researcher.

Inclusion criteria included the following: postmenopausal women aged between 45-60 years; approval of developing metabolic syndrome by a physician; and approved mental, emotional, and cognitive health by selfreporting. Lack of inclusion criteria included affected by cardiovascular disease, diabetes and hypothyroidism, the use of hormone therapy, and performing surgery for total hysterectomy and oophorectomy. Exclusion criteria were performing a total hysterectomy and oophorectomy during the study and not attending the entire training sessions. Out of the 150 patients presented, 22 people did not qualify for inclusion criteria, and 8 people did not consent to participate in the study after hearing the purpose and method of the study. After selecting samples, the nature and manner of program implementation were explained to the patients, and the samples were included in the study by having informed written consent.

\section{Data collection}

The data were collected through a demographic questionnaire, anthropometric indicators, and Orem's requirement form. The demographic questionnaire included personal information (age, marital status, occupation, religion, education, etc.). The duration of completion of the questionnaires by patients was $10-15 \mathrm{~min}$. In the case of lack of literacy, forms were completed and coded by the researcher. Anthropometric information included measurement of height using a SECA stadium meter with a precision of $0.1 \mathrm{~cm}$, while the heels on the ground, legs together, the body in upright position, head and face forward, and drawing a deep breath. Waist Circumference (WC) was measured using a tape with a precision of $0.1 \mathrm{~cm}$ at the middle point of the abdominal region, between the lowest gear of the chest and the iliac bone and precisely in the umbilical circumference.

Measurement of the Hip Circumference (HC) was done using a tape with a precision of $0.1 \mathrm{~cm}$ and the largest area in the serine muscle, the Middle of the Arm Circumference (MAC) using a tape with a precision of $0.1 \mathrm{~cm}$ when the patient's arm was placed at right angles and measured between tip from shoulder and elbow bones. Weighing was performed using SECA digital scale with an accuracy of $0.1 \mathrm{~kg}$, without shoes, standing in the middle of the scale, without assistance and with a thin cloth. Body Mass Index (BMI) was calculated using the ratio of weight (in kilograms) to height (in square meters). Waist to Hip Ratio (WHR) and waist to Height Ratio (WHtR). To determine the educational needs of the participants in the program, the Orem requirement form was used, which included 4 sections, namely patient's general history, general self-care needs, evolutionary needs of selfcare, and self-care needs related to health deficiencies. 


\section{Intervention}

The intervention in this study was carried out as a selfcare education program. The purpose of the self-care program in this study was the formation of a conceptual model of Orem that depends on training needs of patients participating in the program, which was achieved through the completion of the Orem requirement form (Alligood 2011). The program was designed and implemented based on Orem's supportive-educative nursing system, which included a collection of self-care training programs that assist patients in identifying and investigating their needs.

The education package included training the subjects to improve their understanding and awareness of metabolic syndrome and menopause, nutrient regimen, medication regimen, physical activity, and weight loss. The program was conducted in 5 sessions of 45 minutes duration, of which 30 minutes for oral presentation and 15 minutes for questions and answers. The program continued for 5 weeks (one session per week) with a group of 5-7 people. The training started and ended at a certain date provided by 5 research assistants. The assistants were selected by voluntary participation of the key people of the centers that participated in the 20 -hour training class.

The training class was held by researchers with all educational materials, then, the persons were homogenous equally by holding a test. The training programs were conducted in the morning shift and in the selected healthcare centers of Tehran municipality. The training was conducted to provide information to the participants about metabolic syndrome and its relationship to menopause, complications of the disease, dietary consultation (use of fresh vegetables and fruit, low salt and carbohydrate diet, reduced consumption of saturated fatty acids and their importance, and a variety of foods that can be used), medication regimen (the importance of taking them on time, dosage and their effects), and weight loss and physical activity (aerobic sports, type of physical activity and its role in health).

The training program also included educating the participants on how to measure their blood pressure, weight, and blood sugar levels. At the end of each session, the subjects gave educational pamphlets of that session. The final educational material was in the form of a booklet with 5 chapters, which included metabolic syndrome and menopause (chapter I); diet and metabolic syndrome (chapter II); medication regimen and metabolic syndrome (chapter III); physical activity, weight loss, and metabolic syndrome (chapter IV); and how to measure blood pressure, body weight, and blood sugar (chapter V).

The content of the booklet was reviewed and approved by 10 medical-surgical scholars. To evaluate the efficiency of training, the participants were asked two questions at the beginning of each session about the previous session and how they incorporated that at home. It is worth noting that the trainer was available to answer any questions raised by participants via phone if needed. At the end of the study, the subjects were rewarded for their participation. Patients in the control group did not perform any intervention and they continued to have their usual lifestyle as before. At the end of the investigation, they were provided with the educational material and also rewarded as their other counterparts for their participation in this program.

\section{Data analysis}

Eight weeks after the training program anthropometric indicators were analyzed in experimental and control groups using SPSS and STATA with the pre-training indicators. The indicators of primary outcomes were weight, BMI, and WC; anthropometric indicators as secondary outcomes were WHR, WHtR and MAC. To describe the quantitative data from the mean (standard deviation) and to describe the qualitative data, frequency (percent) was used. To analyze the data, the qualitative variables were compared between the two groups using Chi-square test and comparison of quantitative variables between two groups using independent t-test. Given that the centers have been assigned to treatment groups instead of persons, the analyses should be considered as a correlation between persons within a cluster, which was done using STATA software and the SVY environment. In order to compare the before-after results in each group, paired T-test was used. $\mathrm{P}<0.05$ was considered statistically significant in all analyses.

\section{Results}

In the present study, the mean age of the samples in the intervention group was $52.86 \pm 4.40$ years and in the control group $52.06 \pm 4.53$. The average duration of metabolic syndrome in the intervention group was 3.5 years and in the control group 3.87 years. The average age of menopause in the intervention group was 48.2 years and in the control group 47.18 years. In relation to the category of education, the highest frequency was observed in both groups (intervention: $26 \%$ and control: $30 \%$ ) related to the cross-up cycle. About $48 \%$ of the samples 
Table 1. Comparison of demographic characteristics in intervention and control groups

\begin{tabular}{|c|c|c|c|c|}
\hline \multicolumn{2}{|l|}{ Variables } & \multirow{2}{*}{$\begin{array}{l}\text { Intervention } \\
52.86(4.40)\end{array}$} & \multirow{2}{*}{\begin{tabular}{c|} 
Control \\
$52.06(4.53)$
\end{tabular}} & \multirow{2}{*}{$\begin{array}{c}\mathbf{P} \\
0.352\end{array}$} \\
\hline Age* & & & & \\
\hline With metabolic syndrome duration* & & $3.5(2.91)$ & $3.87(3.60)$ & 0.509 \\
\hline Menopausal age* & & $48.2(3.71)$ & $47.18(3.29)$ & 0.039 \\
\hline Height $(\mathrm{cm})^{*}$ & & $157.61(6.11)$ & $158.91(8.10)$ & 0.362 \\
\hline \multirow{3}{*}{ Education $* *$} & Illiterate & $12(20)$ & $11(18.64)$ & \multirow{3}{*}{0.877} \\
\hline & Elementary & $22(36.67)$ & $19(32.2)$ & \\
\hline & Cycle up & $26(43.33)$ & $30(49.15)$ & \\
\hline Married** & $\begin{array}{l}\text { Not married } \\
\text { Married }\end{array}$ & $\begin{array}{c}5(8.33) \\
48(91.67)\end{array}$ & $\begin{array}{l}10(16.95) \\
49(83.05)\end{array}$ & 0.098 \\
\hline Physical activity** & $\begin{array}{l}\text { Little } \\
\text { Higher than average }\end{array}$ & $\begin{array}{l}48(80) \\
12(20)\end{array}$ & $\begin{array}{l}52(86.44) \\
8(13.56)\end{array}$ & 0.570 \\
\hline Cigarette** & $\begin{array}{l}\text { Yes } \\
\text { No }\end{array}$ & $\begin{array}{c}1(1.66) \\
59(98.33)\end{array}$ & $\begin{array}{c}2(3.39) \\
58(96.61)\end{array}$ & 0.516 \\
\hline History of contraceptive use ${ }^{* *}$ & $\begin{array}{l}\text { Yes } \\
\text { No }\end{array}$ & $\begin{array}{l}27(45) \\
33(55)\end{array}$ & $\begin{array}{l}36(61.02) \\
24(38.98)\end{array}$ & 0.214 \\
\hline Family history of metabolic syndrome** & $\begin{array}{l}\text { Yes } \\
\text { No }\end{array}$ & $\begin{array}{l}41(68.33) \\
19(31.67)\end{array}$ & $\begin{array}{l}50(84.75) \\
10(15.25)\end{array}$ & 0.072 \\
\hline Life style** & $\begin{array}{l}\text { Single } \\
\text { With family }\end{array}$ & $\begin{array}{c}4(6.66) \\
56(93.33)\end{array}$ & $\begin{array}{l}6(10.17) \\
54(89.83)\end{array}$ & 0.408 \\
\hline Number of children** & $\begin{array}{l}\leq 4 \\
5 \leq\end{array}$ & $\begin{array}{l}49(81.67) \\
11(18.33)\end{array}$ & $\begin{array}{l}46(79.31) \\
12(20.69)\end{array}$ & 0.767 \\
\hline Wife's job** & $\begin{array}{c}\text { Employee } \\
\text { Free } \\
\text { Retired } \\
\text { Unemployed }\end{array}$ & $\begin{array}{l}8(14.45) \\
15(27.27) \\
27(49.09) \\
5(9.091)\end{array}$ & $\begin{array}{l}11(22.45) \\
19(38.78) \\
18(36.73) \\
1(2.041)\end{array}$ & 0.185 \\
\hline Economic situation** & $\begin{array}{l}\text { Weak } \\
\text { Average } \\
\text { Good }\end{array}$ & $\begin{array}{l}5(8.33) \\
48(80) \\
7(11.67)\end{array}$ & $\begin{array}{l}6(10.17) \\
44(74.58) \\
9(15.25)\end{array}$ & 0.839 \\
\hline Occupation** & House wife & $55(91.67)$ & $56(94.92)$ & 0.529 \\
\hline
\end{tabular}

* Quantitative variables: Mean (SD); $\mathrm{P}<0.05$

Client-Centered Nursing Care

** Qualitative variables: Frequency (\%); $\mathrm{P}<0.05$ 
Table 2. Independent t-test in intervention and control groups before training

\begin{tabular}{|cccc}
\hline Before Training & Intervention & Control & P \\
\hline Weigh & $79.12(11.06)$ & $74.38(10.68)$ & 0.032 \\
\hline Waist circumference & $102.17(9.68)$ & $96.86(10.23)$ & 0.055 \\
\hline Hip circumference & $104.56(8.76)$ & $100.86(9.22)$ & 0.161 \\
\hline Middle arm circumference & $33.79(3.31)$ & $31.89(3.86)$ & 0.067 \\
\hline Waist- hip to ratio & $0.979(0.07)$ & $0.962(0.82)$ & 0.102 \\
\hline Body mass index & $25.09(3.32)$ & $23.35(2.87)$ & 0.015 \\
\hline Waist- height to ratio & $0.64(0.067)$ & $0.60(0.060)$ & 0.043 \\
\hline
\end{tabular}

in the intervention group and $49 \%$ of the samples in the control group were married.

The highest frequency in the context of having physical activity was related to the amount of low activity (48\% in the intervention group and $52 \%$ in the control group). Only $1 \%$ of the samples in the intervention group and $2 \%$ of the samples in the control group were smokers. About $27 \%$ of the intervention group and $36 \%$ of the control group had a positive history in the field of taking contraceptive pills. In relation to the category of developing metabolic syndrome, $41 \%$ of the samples in the intervention group and $50 \%$ of the samples in the control group had a positive family history. Moreover, $56 \%$ of the samples in the intervention group and $54 \%$ of the samples in the control group lived with family.

In association with the husband's occupation categories, the maximum frequency ( $27 \%$ in the intervention group and $18 \%$ in the control group) was related to retirement. About $49 \%$ of the sample in the intervention group and 46 $\%$ of the sample in the control group had 4 children or less.
The highest frequency in terms of the economic situation in the control group (44\%) and in the intervention group (48 $\%$ ) corresponded to the average level. The samples in the intervention and control groups in relation to housekeeping jobs had a frequency of $55 \%$ and $56 \%$, respectively. The average height was $157.61 \pm 6.11 \mathrm{~cm}$ in the intervention group and $158.91 \pm 8.10 \mathrm{~cm}$ in the control group.

The intervention and control groups were matched in all of the individual variables, except for the age of menopause and a family history of metabolic syndrome $(\mathrm{P}<0.05)$ (Table 1).

Independent t-test showed that, intervention and control groups had a significant difference in the pre-training stage in anthropometric indicators such as weight, BMI, and WHtR (Table 2). However, in the post-training phase, there was no significant difference in any of the anthropometric indicators between intervention and control groups $(\mathrm{P}<0.05)$. Contingency confused variables and basic values for each variable were controlled using

Table 3. Independent t-test in intervention and control groups after training

\begin{tabular}{ccccc}
\hline After Training & Intervention & Control & $\mathbf{P}$ & $\mathbf{P}^{\star}$ \\
\hline Weigh & $77.13(11.18)$ & $74.62(10.76)$ & 0.179 & $<0.001$ \\
Waist circumference & $98.31(9.07)$ & $97.23(10.06)$ & 0.651 & $<0.001$ \\
Hip circumference & $100.94(8.03)$ & $100.77(9.10)$ & 0.941 & $<0.001$ \\
Middle arm circumference & $32.71(3.12)$ & $31.93(3.80)$ & 0.355 & 0.464 \\
Waist-hip to ratio & $0.975(0.07)$ & $0.967(0.08)$ & 0.088 & 0.150 \\
Body mass index & $24.46(3.36)$ & $23.42(2.89)$ & 0.451 & $<0.001$ \\
Waist-height to ratio & $0.62(0.06)$ & $0.61(0.05)$ & & $<0.001$ \\
\hline
\end{tabular}

P: Before adjusting the confused variables Client-Centered Nursing Care

$P *$ : After adjusting the confused variables 
Table 4. Paired t-test in intervention group before and after training

\begin{tabular}{|c|c|c|c|}
\hline Intervention Group & Before & After & $\mathbf{P}$ \\
\hline Weigh & $79.12(11.11)$ & $77.13(11.22)$ & $<0.001$ \\
\hline Waist circumference & $102.17(9.73)$ & $98.31(9.10)$ & $<0.001$ \\
\hline Hip circumference & $104.56(8.80)$ & $100.94(8.07)$ & $<0.001$ \\
\hline Middle arm circumference & 33.79 (3.33) & $32.71(3.13)$ & $<0.001$ \\
\hline Waist-hip to ratio & $0.979(0.07)$ & $0.975(0.07)$ & $<0.400$ \\
\hline Body mass index & 25.09 (3.33) & $24.46(3.37)$ & $<0.001$ \\
\hline Waist- height to ratio & $0.64(0.06)$ & $0.62(0.06)$ & $<0.001$ \\
\hline
\end{tabular}

models of regression. Therefore, there were significant differences in anthropometric indicators except for the WHR between control and intervention groups (Table 3).

The results of paired t-test showed that in the intervention group, after the training stages there was a significant decrease in the anthropometric indicators, except for the WHR (Table 4). However, in the control group, there was no significant difference in any of the anthropometric indicators before and after the training stages $(\mathrm{P}<0.001)$ (Table 5).

\section{Discussion}

Based on the findings of this study, it can be concluded that self-care education program improves the anthropometric indicators of postmenopausal women with metabolic syndrome. The study of Taherpour \& Sefidi (2013) showed that training increases awareness of postmenopausal women. Therefore, the implementation of educational programs is the best way to change the attitude, behavior, and empowerment of individuals. In the present study, self-care education derived from the conceptual framework of the Orem model, with the focus on educational needs, led to motivation in patients. The most intriguing result of this education was a change in their anthropometric indicators. For future studies, it is recommended that longer self-care programs should be performed in these patients.

The study of Ejtahed et al. (2014) in determining anthropometric indicators predictive of body fat percentage in adolescents showed that BMI is the most important factor and the WC has the highest interpersonal changes in body fat percentage. Therefore, in the present study, BMI and WC were checked as the main parameters of the study. On the other hand, Banihidari et al. (2012) confirmed the relationship between abdominal obesity and the early stages of atherosclerosis. In this study, a significant relationship was found between anthropo-

Table 5. Paired t-test in control group before and after training

\begin{tabular}{cccc}
\hline Control Group & Before & After & P \\
\hline Weigh & $74.20(10.73)$ & $74.44(10.81)$ & 0.001 \\
\hline Waist circumference & $96.76(10.22)$ & $97.11(10.06)$ & 0.005 \\
\hline Hip circumference & $100.91(9.91)$ & $100.83(9.07)$ & 0.619 \\
\hline Middle arm circumference & $31.86(3.85)$ & $31.90(3.79)$ & 0.545 \\
\hline Waist- hip to ratio & $0.961(0.082)$ & $0.965(0.081)$ & 0.017 \\
\hline Body mass index & $23.31(2.87)$ & $23.39(2.89)$ & 0.001 \\
\hline Waist- height to ratio & $0.60(0.05)$ & $0.61(0.05)$ & 0.004 \\
\hline
\end{tabular}


metric indicators (WC, WHR, and WHtR) of abdominal obesity and the problem of atherosclerosis, among which waist circumference was highlighted.

Considering that abdominal obesity and WC are the criteria for metabolic syndrome, the metabolic syndrome puts people at risk of cardiovascular diseases. Moreover, Rosato et al. (2011) reported a significant relationship between the incidence of breast cancer and metabolic syndrome in postmenopausal women. Given that postmenopausal women with metabolic syndrome are at increased risk for cardiovascular and breast cancer complications, the self-care training program based on the supportive and educational system of the Orem conceptual model can play a preventive role in dangerous complications and modify the anthropometric indicators.

Williams et al. (2013) demonstrated the effectiveness of the intervention with lower cost and tension in preventing metabolic syndrome in women undergoing menopause in the United States. This intervention was a textual training program on nutrition, activity, and rest, which had an impact on the adjustment of BMI in women in a longer time. In the present study, the training program was taken from the Orem self-care model. Training sessions were held in small and participatory groups. Therefore, the effect of self-care training program appeared in a shorter time period in modifying the anthropometric indicators. The study of Ruggirero et al. (2014) described the effect of self-care education on monitoring nutrition and physical activity to control BMI. Similarly, Kong et al. (2012) showed the effect of combined dietary regimen and aerobic exercise as self-control behaviors for weight loss in postmenopausal women.

Cristóvão (2015) showed a positive effect of self-care in managing food and fluid restrictions in patients with chronic renal disease on hemodialysis. The importance of self-care program lies in the fact that it increases the autonomy of patients and improves the ability of patients to take care of themselves. Therefore, the present study is consistent with the previous studies (Ref) in that the training affects the changes in lifestyle and consequently help in controlling anthropometric indicators (weight and $\mathrm{BMI})$.

The results of the study of Zakizad Abkenar et al. (2016) showed the effectiveness of Islamic meditation in improving the self-care behaviors of nutrition, and modifying the weight and BMI of middle-aged patients with diabetes during a 2-month training period. Considering the significant results of this study, the authors predicted that the results can be repeated in other patients with chronic and non-communicable diseases to check which behavioral agents play any role in their development. They also recommended a larger number of samples by individual training and discussion in smaller groups with longer duration. The method and results of the present study are consistent with the study of Zakizad Abkenar et al. (2016). In this study, the implementation and training of self-care programs, which were small and collaborative-supportive group, relied on Orem's theory that evaluates self-care programs from a variety of dimensions, due to the duration of more than two months, also revealed its effects on other anthropometric indicators. Therefore, the importance of grouping and collaborative education is emerging in chronic diseases, so that their educational needs are considered.

In 2014, a field study was conducted in Seoul by Kang et al. (2014) on the relationship between employment and metabolic syndrome in women. This study, however, did not pay attention to the variables of consumption of hormone, the use of cigarettes, and activity levels. Importantly, the present study examined these factors along with other individual variables to maintain of study of influence the confused factors.

According to the statement, prevention of menopause is one of the inevitable stages of life in women. Nevertheless, the complications of this stage can be reduced if there are health knowledge and proper use of it, which could make it an ideal and enjoyable period. Orem's selfcare model is an excellent clinical guide for planning and implementing self-care principles. Patients also take care of themselves, relying on their abilities. This care method is a non-invasive and low-cost method for controlling physical and psychological problems and can be trained easily by health care staff including nurses.

Basically, the goal of self-care education is to preserve patient autonomy, prevent the patient's dynamic lulling and reluctance to recover faster, and to resume daily life activities. This study showed that the application of a self-care program designed based on Orem model was effective on the anthropometric indicators of postmenopausal women with metabolic syndrome. The program, which is designed based on educational needs and with a scientific model approach, is recommended as a nursing intervention in patients with metabolic syndrome. It is also suggested that self-care training programs should be done on other chronic and non-communicable diseases, in different age groups, and with a longer period of time.

Regarding the challenges of this study, there were some confusing factors for the duration of the meta- 
bolic syndrome and menopausal age. These factors were modulated by statistical analyses and the results were re-examined. To determine the educational needs of self-reporting was among the other constraints of this study. The researcher was able to obtain accurate and comprehensive information by providing confidence and motivation in patients. Another problem was the inability to maintain samples in a controlled environment throughout the study. Thus, to prevent the contamination of information, the centers were divided into experimental and control groups. Patients did not meet with each other during that period.

\section{Acknowledgments}

This paper was extracted from the master's thesis of Ms. Badizadeh, Department of Nursing and Midwifery, Iran University of Medical Sciences, Tehran.

\section{Conflict of Interest}

The authors declare no conflicts of interest.

\section{References}

Aggleton, P. \& Chalmez, H., 2014. Nursing models \& nursing practice [R. Tabari, Persian trans.]. Tehran: Boshra.

Alligood, M. R., 2011. Nursing theory: Utilization \& application. Amsterdam: Elsevier Health Sciences.

Asadi Noogaee, A., Zandi, M. \& Nazari, A. 2010. [The learning process and the principles of patient education (Persian)]. Tehran: Pasargad.

Banihidari, M. et al., 2012. [Comparsion of diagnostic value of abdominal anthropometric indicesus carotid intima-media thickness for prediction of atherosclerosis ( Persian )]. Journal of Ardabil University of Medical Sciences, 12(2), pp. 122-31.

Cristóvão, A. F. A. D. J., 2015. Fluid and dietary restriction's efficacy on chronic kidney disease patients in hemodialysis. Revista Brasileira De Enfermagem, 68(6), pp. 1154-62. [DOI:10.1590/0034-7167.2015680622i]

Ejtahed, H. et al., 2014. [Anthropometric indices as predictors of percentage body fat in adolescents (Persian)]. Research in Medicine, 38(1), pp. 25-31.

Hinckle, J. L., 2014. Medical and surgical nursing textbook of Brunner E Suddarth's 2014: Metabolism and endocrine. [N. Dehghan Niri., A. Asadi Noogaee., M. Moosapour, Persian trans.]. Tehran: Jame'e Negar.

Hinckle, J. L. \& Chivier, C. H., 2014. Medical and surgical nursing textbook of Brunner \& Suddarth's 2014: Cardiology. [M. Nickravan Mofrad., H. Amini., S. M. Mahdavi Shahri., Zh. Mohammadalayha, Persian trans.]. Tehran: Jame'e Negar.
Kang, H. T. et al., 2014. Employment is associated with a lower prevalence of metabolic syndrome in postmenopausal women based on the 2007-2009 Korean national health examination and nutrition survey. Menopause, 21(3), pp. 221-6. [DOI:10.1097/GME.0b013e3182987078]

Kong, A. et al., 2012. Self-Monitoring and eating-related behaviors are associated with 12-month weight loss in postmenopausal overweight-to-obese women. Journal of the Academy of Nutrition and Dietetics, 112(9), pp. 1428-35. [DOI:10.1016/j. jand.2012.05.014]

Kwak, E. K., Park, H. S. \& Kang, N. M., 2014. Menopause knowledge, attitude, symptom and management among midlife employed women. Journal of Menopausal Medicine, 20(3), pp. 118-25. [DOI:10.6118/jmm.2014.20.3.118]

Rosato, V. et al., 2011. Metabolic syndrome and the risk of breast cancer in postmenopausal women. Annals of Oncology, 22(12), pp. 2687-92. [DOI:10.1093/annonc/mdr025]

Ruggiero, L. et al., 2014. Diabetes island: Preliminary impact of a virtual world self-care educational intervention for African Americans with type 2 diabetes. JMIR Serious Games, 2(2), p. e10. [DOI:10.2196/games.3260]

Speroff, L. \& Fritez, M., 2011. Women's clinical endocrinology and infertility. [M. Valadan, M. H. Ghorbani., O. Gooran Orimi O, Persian trans.]. Tehran: Nasle Farda.

Taherpour, M. \& Sefidi, F., 2013. [The effectiveness of education on the knowledge and attitude towards menopause symptoms and complications in postmenopausal women (Persian)]. Journal of Zanjan university of Medical Sciences, 21(84), pp. 92-101.

Williams, L. T. et al., 2013. The 40-something randomized controlled trial to prevent weight gain in mid-age women. $B M C$ Public Health, 13, p. 1007. [DOI:10.1186/1471-2458-13-1007]

Zakizad Abkenar, M. et al., 2016. The effect of Islamic care method on nutritional self-care, anthropometric indices and blood pressure in diabetic patients. Journal of Mazandaran University of Medical Sciences, 26(136), pp. 36-53. 
August 2017 . Volume 3. Number 3

Client-Centered Nursing Care

188 